\title{
Creative Osmosis: Teacher Perspectives of Artist Involvement in Professional Development
}

\author{
Bernard W. Andrews \\ Faculty of Education, University of Ottawa, Ottawa, Canada \\ Email: b.w.andrews@uottawa.ca
}

Received August $31^{\text {st }}, 2012$; revised September $28^{\text {th }}$, 2012; accepted October $14^{\text {th }}, 2012$

\begin{abstract}
This inquiry examined the impact of a professional development program in the arts for teachers over a three-year period. The summer program focused on the integrated arts and was offered in partnership with Canada's cultural institutions and with the involvement of professional artists. The research focused on the teachers' personal growth and professional practice by employing a multi-perspectives methodology entitled Integrated Inquiry. The inspirational settings in cultural settings, the creative learning activities with artists, and the opportunities to discuss and reflect on their personal perspectives promoted the teachers' personal growth and professional practice. Participation in a wide variety of creative arts activities in cultural settings increased the participants' willingness to teach the arts in their own classrooms. These experiences enhanced their tolerance for ambiguity and sensitivity to different learning styles. The reflective journal was a powerful tool for making the practical theoretical. It enabled them to relate arts experiences to learning theory and to develop and nurture new ideas. Major obstacles to implementing the arts in schools were inadequate resources, limited peer support, insufficient expertise to assess student achievement effectively, and lack of time. Teachers could overcome these obstacles by engaging in arts advocacy, developing cross-curricular arts themes, enrolling in upgrading courses in evaluation, and adopting an integrated approach to curriculum delivery, respectively.
\end{abstract}

Keywords: Arts Partnerships; Professional Development Arts; Artists Teaching Teachers

\section{Introduction}

In response to concerns by the teaching profession, education faculties across Canada have developed new partnerships with their stakeholders to deliver programs that are relevant and effective (Andrews, 2002; Gurney \& Andrews, 1998, 2000). In Ottawa, Canada's capital city, an innovative integrated arts in-service program for teachers was developed by the Arts Education Consortium, a partnership of Canada's national cultural institutions and the Faculty of Education at the University of Ottawa. The program features creative artists working with classroom teachers in professional development to improve the teaching of the arts-dance, drama, music and visual artswithin the school curriculum.

The Arts Education Consortium is comprised of the Canadian Conference of the Arts, the Canadian Museum of Civilization, the National Arts Centre, the National Gallery, the National Library, the School of Dance, and the University of Ottawa. ${ }^{1}$ The Consortium supports teacher development and research in arts education. ${ }^{2}$ The Odyssey Project is a multi-year research project intended to assess the effectiveness of the Consortium's integrated arts partnership program for enhancing teachers' arts learning and developing their instructional effectiveness. ${ }^{3}$ The Project involves several phases: the first two

\footnotetext{
${ }^{1}$ The Consortium evolved into a loosely-coupled partnership whereby partners became involved in a broader range of university programs, such as $\mathrm{B}$. Ed. and M. Ed., in addition to the A. Q. program.

${ }^{2}$ Teacher development subsumes pre-service (i.e., Teacher Education), in-service (i.e., Additional Qualification courses), and Graduate Studies (M. Ed.). ${ }^{3}$ The Odyssey Project was funded by the Laidlaw Foundation and the University of Ottawa.
}

phases focused on the on-site program at the cultural institutions whereas this study focused on teachers' practices in their own classrooms. This research, entitled Creative osmosis: Teacher perspectives on artist involvement in professional development (Phase 3), examined the impact of the integrated arts partnership program on teachers' experiences in the field by those who successfully completed the program over a threeyear period.

\section{Previous Research}

Phase 1, entitled The Odyssey Project: Fostering teacher learning in the arts, focused on a description of those classroom factors that promote changing teachers' beliefs and practices (Andrews, 2008a). The study combined themes from journals, classroom observations and video sessions of the integrated arts partnership program during a summer session. Findings indicate that it is an emerging group culture characterized by a sense of community, comfort and mutual support which fosters trust, emotional openness and personal risk-taking. These aspects of the program enable teachers to explore their own creativity, examine their thoughts and feelings, acknowledge each other's views, understand different perspectives, and engage successfully in artistic activities. Further, they develop an understanding of the significance of the arts to society and for their own professional practice.

Phase 2, entitled Seeking harmony: Teachers' perspectives on learning to teach in and through the arts, examined teachers' perspectives on their experiences with professional artists in the integrated arts partnership program (Andrews, 2010). The study 
combined questionnaire, focus group and survey data. Findings indicate that when artists, selected for their interest in education and ability to collaborate with teachers, are involved in professional development, teachers acquire the confidence to express themselves freely, they are willing to teach the arts in their own classrooms, they realize the potential and value of the arts within the school curriculum, and they develop arts-specific teaching expertise. Further, the teachers' sensitivity to their own creativity and openness to experimentation is heightened, and an awareness of the potential of the arts to develop a student's imagination, intuition and personal expressiveness is developed.

\section{Arts Education Context}

In Ontario, Canada's largest province, classroom teachers are expected to integrate the arts into the general curriculum (Ontario Ministry of Education, 1998, 2009), seldom with sufficient training or background (Pitman, 1998; Wilkinson, Emerson, Guillaumant, Mergler, \& Waddington, 1992). This is also a common problem in other jurisdictions (Bresler, 1992; Oreck, 2004; Taggart, Whitley, \& Sharp, 2004). Many elementary teachers lack sufficient expertise to teach the arts effectively (Patteson, 2002a, 2002b; Smithrim \& Upitis, 2001), and consequently teaching the arts causes anxiety for them and often leads to avoidance (Oreck, 2004; Taggart, Whitley, \& Sharp, 2004). To assist teachers acquire the requisite expertise, a unique summer arts program was developed by the Arts Education Consortium. This program focused on the integrated arts, and it featured teachers undertaking creative learning on-site at Canada's cultural institutions with professional artists and completing a follow-up action research project in the fall session. ${ }^{4}$

Partnerships between arts organizations and educational institutions are an effective approach to arts education (Doherty \& Harland, 2001; Smithrim \& Upitis, 2001). The collaboration that ensues provides expertise, insights and funds not readily available to teachers and students (Irwin \& Kindler, 1997; Upitis, Smithrim, \& Soren, 1999). Artist involvement in schools (Oreck, 2004; Upitis, Smithrim, \& Soren, 1999) and in professional development programs (Patteson, 2002c; Upitis, 2005) encourages teachers to teach the arts. Such collaboration has also been effective for developing the arts expertise of beginning teachers (Andrews, 1995, 1999) and motivating them to undertake arts instruction in their own classrooms (Andrews, 1997, 2006). Successful partnerships strengthen the connections between schools and their communities (Bailey, 1998), and mutual respect for each partner's values, goals and organizational culture are developed (ARTS, Inc. \& Performing Tree, 2000). Organizations pool resources and ideas, share workloads, expand funding bases, gain political clout, and strengthen professional development opportunities for both teachers and artists through their involvement in partnerships (Arts Education Partnership, 2001).

\section{Methodology: Integrated Inquiry}

Integrated Inquiry was employed throughout each phase of The Odyssey Project. It is an approach to research that seeks to examine instructional issues from a variety of perspectives and acquire a more comprehensive understanding of a research ${ }^{4}$ Additional Qualifications (AQ) are upgrading courses for practicing teachers which are unique to Ontario. issue. This may be achieved by combining multiple qualitative and/or quantitative data or alternately, administering a single protocol in different years of a program. This form of inquiry adopts the metaphor of the professional composer; that is, one who combines multiple qualitative (e.g., instrumentation, orchestration) and/or multiple quantitative (e.g., meter, tempo) musical elements in a seamless web of integration (Andrews, 2008b). Similarly, researchers using Integrated Inquiry can employ multiple qualitative and/or multiple qualitative data sources. For example, different protocols can be administered to the same group in a study, or the same protocol can be administered to different groups over several years. Both of these approaches enable researchers to acquire a multi-dimensional perspective on the research problem. To substantiate analyses and epistemological stances, combining data from multiple protocols in this way is supported in educational research (Creswell, 2002; Miles \& Huberman, 1994; Patton, 1990; Stake, 1995). Integrated Inquiry is particularly useful for research with a limited amount of data. Previously, the writer has successfully employed this method of research in several studies (e.g., Andrews, 2002, 2005, 2006, 2008a, 2010).

This study, entitled Creative osmosis: Teacher perspectives on artist involvement in professional development, examined the impact of the arts partnership program on teachers' personal growth and professional practice in different years of the program with professional artists. Nine teachers, all of whom had successfully undertaken the program in one of the three years that the program was offered, volunteered to participate in this study: 2 of 18 enrolled in Year 1; 4 of 12 enrolled in Year 2; and 3 of 10 enrolled in Year 3. Of these, 7 were female and 2 male; 7 worked in the elementary and 2 in the secondary panel; and 5 identified themselves as subject specialists, 3 as generalists, and 1 in administration (i.e., a consultant). All the participants had taught in publically-funded schools with a range of 3 to 18 years of teaching experience. Only one of them indicated expertise in an arts discipline (i.e., drama) (Table 1). Each of the teachers completed an in-depth questionnaire on the impact of the program on their personal growth and professional practice, thereby submitting nine data sources across three different years of the program (Figure 1). The questionnaire was developed in collaboration with the Consortium partners and designed to examine teachers' experiences in the field as a follow-up to previous studies in The Odyssey Project which focused on the on-site program at the cultural institutions (Andrews, 2008a, 2010). The questionnaire focused on the teachers' beliefs and practices in arts education, theory-practice integration within the program, obstacles to teaching the arts in schools, and recommendations for improving professional development in the arts for teachers (Table 2). Data was entered into NVivo, a qualitative software program, and it was coded, analyzed, cross-referenced, and interpreted by the principal investigator and research assistants using the constant comparative method (Stake, 1995).

\section{Multiple Perspectives}

\section{Teacher Beliefs and Practice}

The teachers reported that the key aspects of the summer arts course that promoted their personal growth were the inspirational settings of Canada's cultural institutions, involvement in a variety of creative activities with artists and their classmates, 
Table 1.

Expertise of the teachers.

\begin{tabular}{ccccc}
\hline Number & Gender & Panel & Background & Year \\
\hline 1 & M & E & Religion & Year 1 \\
2 & F & E & Generalist & Year 1 \\
3 & F & E & French/Phys Ed. & Year 2 \\
4 & F & E & Drama & Year 2 \\
5 & F & E & Curriculum Consultant & Year 2 \\
6 & F & S & Drama & Year 2 \\
7 & F & E & Generalist & Year 3 \\
8 & F & E & Generalist & Year 3 \\
9 & M & S & Special Education & Year 3 \\
\hline
\end{tabular}

Table 2.

Questionnaire.

Please complete each of the following questions. Feel free to use the reverse side of the questionnaire, should you require additional space. Teacher Beliefs and Practice:

1) What aspects of the summer arts course promoted your personal growth? Explain.

2) Have your beliefs concerning the arts in education changed as a consequence of completing a professional development course in the arts? Please elaborate.

3) How did the course impact on your classroom practice (e.g.,

teaching strategies, assessment, etc.)? Please elaborate.

Theory-Practice Integration:

1) When were this theory and practice effectively integrated within the course structure?

2) Were the concepts and skills you learned applicable to the classroom setting? Please elaborate.

3) In what ways did the reflective journal contribute to the integration of theory and practice?

Obstacles:

1) When you implemented an arts lesson, what difficulties did you encounter (e.g., timing, gender differences, children's abilities, etc.)?

2) How did you overcome such obstacles?

Recommendations:

1) For you to pursue additional professional development in the arts, what kind of expertise would be valuable to you?

2) Do you have any suggestions to improve the organization and delivery of future professional development programs? Please describe.

and the opportunity to discuss and reflect on their personal perspectives. Together the setting, the arts activities, and the reflective discussions enabled the teachers to explore and discover new aspects of themselves and develop their expertise, thereby developing the confidence and willingness to teach the arts in their own classrooms.

[It was] the challenges to create in different areas of the arts: soundscapes; choreograph a dance using grid (clap your ankles); and declaiming Romeo and Juliet at the National Gallery of Canada. These made us more comfortable with exploring the unknown and showed me again the value of spontaneity and play.

Undertaking professional development with artists on-site at cultural institutions changes the classroom dynamics. The spaciousness of the galleries, concert halls, and studios was in stark

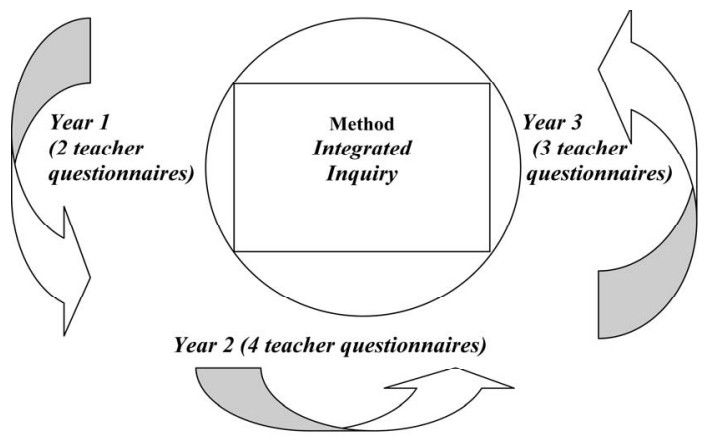

Figure 1.

Data sources for the study.

contrast to rectangular school classrooms, often without windows. These settings encouraged teachers to engage in creative activities and reflect on their learning. This finding is consistent with comments by participants in the two previous phases of The Odyssey Project (Andrews, 2008a, 2010) and in the arts education literature (Arts Education Partnership, 2001; ARTS, Inc. \& Performing Tree, 2000).

Artistic engagement in cultural settings did not so much change beliefs as it reinforced and strengthened the teachers' extant beliefs in the value of the arts. By enabling them to get in touch with their inner selves, the teachers voiced a stronger appreciation of the value of the arts for enhancing personal learning and understanding.

I think I have always valued the importance of creativity and how the arts develop this ability, but the course enabled me to feel it on a more personal level by having me live it.

And...

I always believed that the arts must be a "necessity" for the well being of human kind. After this course, I was even more a strong believer that the arts are teaching us not only to surpass our limits but to discover our inner world.

Engagement with artists in professional development enables teachers to learn how to teach creatively and encourage their students to express themselves through artistic activities in a variety of art forms (Patteson, 2002a, 2002b; Upitis, 2005). In this study, the teachers learned how to express their own feelings in different art forms, and they realized that connections between the arts and other subjects could be developed from an experiential basis and not just from links organized conceptually. Personal experience could serve as a starting point for effective curriculum development.

The course also showed me how the arts can integrate many other more academic subjects because I was so actively involved in the process, not just learning intellectually about it. I found myself constantly thinking of links to math, history and science.

And...

I was shown by professionals in dance, music, theatre how to try and meet some of the Ministry's expectations for the arts by integrating across the curriculum and also 


\section{B. W. ANDREWS}

with the ability to pull more lessons out of personal experiences.

Arts integration is well-established in the educational community as a viable strategy for the teaching of non-arts subjects. Dance, drama, music and the visual arts expand the imagination and enrich the school curriculum (Patteson, 2002a, 2002b; Upitis, 2005). Most importantly, the arts provide a variety of ways for students to learn which is congruent with different learning styles (i.e., auditory, visual, kinaesthetic). However, many teachers lack the confidence to teach the arts in their own classrooms because of a lack of expertise (Oreck, 2004; Taggart, Whitely, \& Sharp, 2004). In this study, participants indicated that their engagement in a wide variety of arts activities throughout the course increased their willingness to teach the arts in their own classrooms and their confidence to do so. Moreover, these arts experiences enhanced their tolerance for ambiguity in the classroom and their sensitivity to different learning styles.

I take more risks and I appreciate the "chaos" of innovation, the students' ideas, experimentation, errors, and the participation of the children.

And...

Now I have to re-design lesson plans to meet different learners learning styles. Teaching strategies were multiplied as it showed me how an art lesson can be transformed into science, math, physical education and language arts.

Through participation in the summer sessions involving professional artists, teachers experienced a significant shift in their beliefs and practices about arts instruction. Prior to the course, teachers did not believe they could successfully teach the arts in their classrooms and lacked the confidence to do, primarily due a lack of expertise in the arts disciplines. This situation is common in many jurisdictions throughout North America and elsewhere (Pitman, 1998; Taggart, Whitely, \& Sharp, 2004). After engaging in a broad variety of artistic activities with professional artists in cultural settings and reflecting on their learning, the participants' confidence increased substantively, and they subsequently taught the arts in their own classrooms. This shift in beliefs and practices is consistent with previous studies involving professional artists in both teacher education (Andrews, 1995, 1997, 1999, 2006) and professional development (Andrews, 2008a, 2010; Patteson, 2002a, 2002b; Smithrim \& Upitis, 2001; Upitis, Smithrim, \& Soren, 1999) programs.

\section{Theory-Practice Integration}

Theory and practice in the program were effectively integrated for the teachers through a combination of artist demonstration and explanation of arts activities, and teacher reflection and discussion on the experiential activities and course resources.

During the classes, we had discussions to elaborate on what we had learned. We used a personal journal to record our daily reflection on theory and practice. The professional artists delivering various segments of the course would elaborate on which theory/practice they were utilizing.
And...

While the course participants were actively involved in practical applications of arts programming, we were given lots of time to devote to discussing how this would work in a classroom setting. Connections were made to the arts curriculum of Ontario.

Reflective practice is a common approach to instructional practice in the teaching profession (Jindal-Snape \& Holmes, 2004; Newton, 2004; Osterman, 1990). Unless a teacher undertakes to do so, however, reflection is not a component of traditional disciplined-based arts instruction (e.g., inter-disciplinary, multi-disciplinary, parallel disciplines), nor arts integration strategies (e.g., arts \& crafts, multicultural arts, integrated arts). However, this aspect of the program provided an effective vehicle for integrating theory and practice, transferring skills, and enabling teachers to internalize a range of arts learning. The teachers recognized the value of reflection within the program's curriculum for broadening their awareness of the opportunities of integrating the arts into their classroom teaching and for their own personal development.

In a matter of a few weeks, a teacher with little or no arts background had at their disposal a plethora of hands-on lessons, documentation, bibliographies, living resources, contacts throughout the city, calendars of events, and a follow-up personal development course to complete.

Professional development programs in the arts historically focus on the development of technical skills. For example in Ontario education, a series of Additional Qualification courses are offered by faculties of education in dance, drama, music and visual arts. These courses are designed to develop the teachers' expertise in the discipline and to provide disciplined-based approaches to classroom instruction. In the summer program the teachers commented that the curriculum was focused on process not on skill acquisition. There was some frustration expressed that the nature of the course did not enable them to develop technical skills so that they could not take their students beyond an engagement in exploratory arts activities.

The activities consisted of exploring the medium, rather than technical skills per se... I feel my own lack of technical skill in music and dance keeps me from taking students to the "next" level.

The number of hours in the summer arts program is mandated by the Additional Qualification program administered by the Ontario College of Teachers. Consequently, more hours would be required to develop teachers' skills further in each of the arts subjects, in addition to the arts integration focus of the program. There have been similar concerns about an integrated arts approach in the literature with critics claiming that teachers should acquire arts expertise prior to taking such a program (Best, 1995; Clark, 1995; Conway, Hibbard, Albert, \& Hourigan, 2005; Kindler, 1987). However, there are those experts who argue just as pervasively that arts integration should be the starting point for teaching the arts and teachers can acquire additional technical skills as needed (Freedom, 1989; Galt, 1994; Berghoff, Borgaman, \& Parr, 2004).

The reflective journal was a powerful tool for making the practical theoretical. It enabled the teachers to understand the relationship of their arts experiences to learning theory and to 


\section{B. W. ANDREWS}

develop and nurture new ideas. Both of these aspects of the journaling experience assisted them to more effectively integrate theory and practice, and contributed to their personal growth and development.

I feel that reflection is always important to the learning process, so taking the time to reflect on the practical work we did was essential to our absorption of what we had learned. It gives you the time to think about what worked and what didn't for us, and what might work with a group of students and what might not.

And...

The act of reflection demands thought and gives one time to ask oneself how one felt about a dramatic involvement or personal contribution to the group effort. This time of reflection allows new ideas and thought to surface around the "experience". Sometimes, further discussion will follow. Ideas mature and develop. Real personal growth is possible over time, once the journal writing becomes a regular habit.

Overall, the participants' theory-practice integration is an outcome of engagement in a broad range of creative activities in dance, drama, music and the visual arts with professional artists, implementing the program on-site in cultural institutions which inspired them to engage in arts experiences, and the use of journals to reflect and discuss their personal perspectives. Taken together these three aspects of the program raised the teachers' confidence and willingness to teach the arts in their own classrooms.

\section{Obstacles}

Four obstacles emerged from the teachers' comments describing the difficulties they experienced implementing arts lessons: making time within the curriculum; acquiring arts resources; obtaining support from other teachers on staff; and undertaking effective arts evaluation.

1) Time is a serious constraint on teachers, particularly given the compression of the curriculum with the elimination of one-year from the school curriculum (i.e., Ontario Academic Credits/Grade 13).

A re-occurring obstacle is always having enough time to assist those children whose abilities require more time and experience.

In Ontario, there were initially 13 grades which were reduced to 12 commencing in 2003. Consequently, the entire elementary and secondary curriculum was affected by the expectation by the Ministry of Education to do more in less time. Further, the Ministry implemented standardized testing in grades 3, 6, 9 and 10 with the result that teachers focus on those subjects that promote numeracy and literacy, often at the expense of those that promote creativity and aesthetic experiences. The standardized testing is administered by the Education Quality and Accountability Office (EQAO) which was established in 1996 by the provincial legislature (Government of Ontario, 1996).

2) The elementary teachers found it difficult to acquire the resources to effectively deliver a wide range of activities as there were financial constraints and space limitations.

You are not in an art studio with easily accessible supplies for a whole morning with lots of room to work in and put up the work. Also, there is always a storage problem... where to keep all the visual arts supplies? And what about the drums that students have made and their beautiful but huge masks? We want them around to use them and enjoy.

During the 1990's, the Ontario educational system was subject to considerable financial restraint as the provincial government attempted to eliminate the deficit and reduce the debt. School boards were amalgamated, arts programs were eliminated, small schools closed, and faculties of education restructured (Gurney \& Andrews, 1998, 2000). Many schools were simply unable to provide the arts supplies and equipment required to operate effective programs, especially musical instruments. The situation is analogous once again to the current situation where teachers' incomes are being restricted, benefits removed, and budgets slashed by the provincial government to cope with an ever-increasing debt load (Government of Ontario, 2012).

3) Teachers reported that their colleagues did not always support their efforts.

The "resistance" I get from teachers... is that they don't feel the lesson will always work with the boys. The biggest concern always revolves around gender issues, especially in the areas of drama and dance!

Teachers predominantly focus the instruction on for numeracy and literacy outlined in Ministry of Education curricula due to the emphasis on provincial testing (Government of Ontario, 1996). Arts activities are sometimes viewed as frivolous, especially if they are taught poorly, and they do not contribute directly (i.e., a causal effect) to increasing test results (Upitis, 2005). Large ensemble activities, such as choir, band, dramatic play, or dance, can also result in serious classroom management problems if not implemented by a capable teacher (Andrews, 2011). Perhaps it is not surprising then that, given the pressures of standardized testing and the element of risk in teaching the arts, teacher-colleagues are not always supportive of arts initiatives.

4) Undertaking arts evaluation was a major concern to the teachers. They indicated an awareness of its importance but a frustration with implementation, given the large number of expectations outlined in the curriculum.

I find it difficult also to evaluate each individual student considering all the expectations we are supposed to deliver throughout the year. It is a sheer impossibility.

And...

I guess I have sometimes found it difficult to be nonjudgmental about a student's actual ability. We were told in our course that participation is what matters most... Also, if something is a "personal" effort, should you suggest improvements? Then you have the arts exceptions from the Ministry. I find all this rather confusing.

Although the arts curriculum is mandated to ensure that students achieve the arts expectations (Ontario Ministry of Education, 1998, 2009), many teachers lack the expertise to teach and evaluate achievement in the arts disciplines effectively. Consequently, there is a tendency to avoid doing so (Patteson, 2002a, 2002b; Smithrim \& Upitis, 2001). This is a common problem in many jurisdictions, not just in Ontario but also across North 
America and internationally (Bresler, 1992; Oreck, 2004; Taggart, Whitley, \& Sharp, 2004). Moreover, teachers are generally more comfortable undertaking quantitative (e.g., true/ false, analogy, fill-in-the black, matching, short answer) rather than qualitative (e.g., artworks, portfolios, performances) assessments. The former are efficient and less-consuming than the latter which require the skills to develop contextual criteria (e.g., rubrics) and justify one's professional judgement to students, parents and administrators. Consequently, many teachers experience increased stress when evaluating student achievement in the arts (Andrews, 2011; Oreck, 2004; Patteson, 2002a, b and c).

The teachers, although they had some suggestions for overcoming obstacles, were tentative and recognized that more long-term solutions were required. To obtain resources, advocacy was recommended, and where this was not successful, scaling down projects seemed to be the only alternative. To develop colleague support, teachers suggested identifying schoolwide curricular themes and organizing arts activities in support of them. School meetings and professional development days were also identified as opportunities to solicit support for arts experiences for the students. Teachers recognize the need for evaluation skills in the arts and see this as a key role for professional development. To overcome the lack of time to deliver the arts within the curriculum, an integrated, open-ended approach was suggested.

When giving a lesson, I rely more on a holistic approach, and since I teach at the elementary level, I want the student to have acquired more practice than theory. I hope to expose students to a positive hands-on discovery celebration of the arts in themselves and others.

\section{Recommendations}

The teachers clearly articulated an interest in acquiring additional technical skills in the arts disciplines, in arts assessment, and integrating the arts across the curriculum. Indeed, these skills were not viewed in isolation but viewed by the participants as inter-related.

I would also see that integrating the arts at a school level needs further exploration. How does a person integrate with integrity? Theory proves that you can't integrate without having subject specific knowledge and skills well developed in the first place. Do you integrate subjects into the arts, or the arts into other subjects?

There was strong support for offering the course in Canada's cultural institutions as these locations provide inspiration to pursue the arts personally and motivation to use them in one's practice.

The format was great! The venues were perfect! The teacher/mentor was exceptional. Everyone in the course was fully committed to the process. It was the best two weeks that I have ever given myself. The artist in me was set free!

The notion of the "artist within" was a powerful tool for releasing the teachers' personal creativity. One individual suggested that the focus at some point might shift to "teacher development" which has more personal meaning for practitioners.
I felt that the beginning of the course should be more focused on the development of us as people and artists, which it was. But the second half of the class, I would have liked more of an emphasis of the deve- lopment of us as teachers. Once our batteries had been recharged somewhat, we were ready to think of school again and how we could use this information.

\section{Integration of the Data}

Analysis and interpretation of the data determined that the comments of the participants were similar across all three years of the study on each of the questions. The only noticeable difference was the concern expressed by some of the teachers in the second and third years of the program about the implementation of the revised expectations in the Ontario arts curriculum and its focus on assessment (Ontario Ministry of Education, 2009). This was to be expected given the shift by the Ministry of Education for detailed documentation of assessments for learning (diagnostic), assessment as learning (formative), and assessment of learning (summative). Overall, three major themes emerged across all the data:

- the impact of the arts on children in the classroom;

- the impact of the arts on the teachers themselves; and

- teachers' views on action research.

\section{Impact on Children}

Across the data, comments were made with respect to the impact of the arts lessons on students. These comments focused in two areas: the impact on boys and the impact on timid students. Teachers reported that the boys, who tend to be selfconscious about their bodies and tend not to participate readily in dance and drama, were more engaged in the arts than usual, although not with the focus and sense of completion of the girls.

I found that since incorporating these lessons into my program, my boys hook in more easily and find themselves enjoying art activities. The use of masks for drama and dance were a liberating experience for many self-conscious students.

And...

During the implementation of my action project, I brought what I learned in my water-color class to a small group of boys, who were not very motivated to do art [...] to take their time and really work on their paintings [...] when the next class came up, they didn't want to work on their previous work, even though it wasn't complete. They preferred to start something new.

Teachers also indicated that the arts encouraged introverted students to participate more readily in classroom instruction.

Some of my more timid students are now more actively involved. I think that, like me, they enjoy the play element, but they take it seriously too.

And...

Making dramas and learning basic drumming technique sparked interest in music from many other cultures. Stu- 
dents saw and heard with new eyes and ears. Many children who shied away from such activities because they "didn't feel they were any good at it" found that there was a place for them that they could be successful. One student discovered that he could paint and called himself Nagi Van Gogh.

\section{Impact on Teachers}

The teachers indicated that the course experience brought them in touch with their inner selves, and they learned that they had expertise that they were unaware of. This increased their confidence and willingness to teach the arts in their own classrooms.

Before that course, I had always considered myself to be good in drama and music, but not necessarily in dance and visual arts. I discovered through the course that I am good at all of the arts.

And...

I felt that the course's emphasis was on the development of us as artists rather than us as teachers. I definitely felt that I grew as an artist during that experience, and because of that, it has impacted my classroom.

\section{Action Research}

The action research project was intended to provide an opportunity for teachers to test and refine their newly-acquired arts expertise in the field. However, it received mixed reviews as a vehicle for integrating theory and practice by the participants in the study. Those in favor stated that it enabled them to continue their personal arts learning beyond the completion date of the course.

Because of my action research project (a personal development learning water-color painting), I have continued to take art courses, and am very pleased with the results. I have explored water-color painting for the past two years, and I am now interested in taking courses in drawing.

However, those teachers opposed to the action research project found the complexity of designing and implementing a project difficult to undertake, given their responsibilities in the classroom. Moreover, there was the additional challenge of assisting teachers throughout the fall term across Eastern Ontario on an on-going basis by Faculty of Education staff. Due to the implementation problems, the action research project was subsequently removed from the program.

My action research project (organize workshops for teachers on integrated arts) was mostly an administrative exercise in frustration.

\section{Implications for Professional Development}

The findings of this inquiry reinforce previous research studies that demonstrate the effectiveness of artist involvement in professional development for improving teacher expertise in the arts (Andrews, 2008a, 2010; McVey \& Wilson, 1992; Patteson, 2002c; Upitis, 2005). Further, they provide direction for the development of the arts in professional development programs. Artist-teacher collaboration in a wide range of creative learning activities within professional development enables teachers to develop confidence and encourage them to teach the arts in their own classrooms (Myers, 2005). Artistic involvement sensitizes teachers to different learning styles and develops in them a tolerance for ambiguity and an appreciation of divergent thinking (Oreck, 2004; Upitis, 2005). Collaboration with artists in experiential activities fosters creativity and in-depth learning (Rowe, Castaneda, Kaganoff, \& Robyn, 2004). A focus on reflection, both through discussion of personal experiences and reflective journals, provides a vehicle for linking theory and practice (Wilkinson, 2000).

Balancing discipline-based knowledge with integrative teaching strategies appears to foster teachers' personal arts learning and also a willingness to teach the arts in their own classrooms (Andrews, 1997, 2006; Ingram \& Reidel, 2003). In contrast, teaching an arts discipline without reference to the classroom context (e.g., a discipline-based workshop) has not been as successful for encouraging teacher involvement in the arts (Dorn \& Jones, 1988). Education faculties should consider developing in-service programs that balance arts knowledge and skills with integrative activities across the curriculum. However, such integrative activities must also foster learning in each of the arts disciplines to achieve a balanced approach (Brophy \& Alleman, 1991; Berghoff, Borgaman, \& Parr, 2003). Artist involvement in creative learning activities enhances the possibility of achieving this goal.

\section{Concluding Comments}

This inquiry focused on an examination of the involvement of artist-teacher collaboration in professional development on teacher practice. Findings indicate that it was the inspirational settings in cultural institutions, creative learning activities with artists, and the opportunities within the program to discuss and reflect on their personal perspectives that promoted the teachers' personal expertise. Participation in a wide variety of arts activities in cultural settings increased their confidence and willingness to teach the arts in their own classrooms. The arts activities with professional artists within the program enhanced their tolerance for ambiguity and sensitivity to different learning styles. The reflective journal was a powerful tool for making the practical theoretical. It enabled them to relate arts experiences to learning theory, and to develop and nurture new ideas.

The major obstacles to implementing arts lessons in the schools were inadequate resources, limited peer support, insufficient expertise to assess student achievement effectively, and lack of time. These obstacles could be addressed through teachers engaging in arts advocacy, developing cross-curricular arts themes, enrolling in upgrading courses in evaluation, and adopting an integrated approach to curriculum delivery, respectively.

The findings of this study will be useful to those faculties of education contemplating in-service programs involving artistteacher collaboration. Further inquiry needs to be undertaken to determine best practices for artist participation in in-service and also to understand the experienced practitioners' vision of appropriate professional development. Such knowledge would enable faculties of education to develop partnership courses that effectively enhance teachers' arts learning and instructional expertise in the arts. 


\section{B. W. ANDREWS}

\section{Author's Bio}

Bernie Andrews is Professor of Education at the University of Ottawa. He has several years of experience in teaching, administering and evaluating music and arts programs in school and university settings. Currently, he teaches music certification and graduate arts and creativity courses in the Faculty of Education at the University of Ottawa. His research focuses on arts education partnerships, interactive teaching strategies, musical creativity, teacher development, and research methods. Currently, Dr. Andrews is principal investigator of the Social Sciences and Humanities Research Council (SSHRC) project, entitled New sounds of learning: Composing music for young musicians, in partnership with the Canadian Music Centre and the Ottawa Catholic School Board.

\section{REFERENCES}

Andrews, B. W. (1995). Re-designing the arts curriculum of teacher education: A collaborative approach. Canadian Journal of Research in Music Education, 36, 33-39.

Andrews, B. W. (1997). Assessing the effect of collaborative approach to program delivery in arts teacher education. McGill Journal of Education, 32, 163-176.

Andrews, B. W. (1999). Side by side: Evaluating a partnership program. International Electronic Journal of Leadership in Learning, 3. http://ijll.synergiesprairies.ca/iejll/index.php/ijll/article/view/479

Andrews, B. W. (2002). Governance and accountability: The effectiveness of teacher provided in-service in a university setting. International Electronic Journal of Leadership in Learning, 6.

http://ijll.synergiesprairies.ca/iejll/index.php/ijll/article/view/438

Andrews, B. W. (2005). Bridge over troubled waters: Policy development for Canadian music in higher education. Music Education Research, 7, 101-118. doi:10.1080/14613800500042166

Andrews, B. W. (2006). Re-play: Re-assessing the effectiveness of a collaborative approach to program delivery in arts teacher education. International Review of Education, 55, 443-459.

doi:10.1007/s11159-006-9003-2

Andrews, B. W. (2008a). The Odyssey Project: Fostering teacher learning in the arts. International Journal of Education and the Arts, 9. http://ijea.org/

Andrews, B. W. (2008b). Integrated inquiry: Transforming multiple research perspectives. In S. Kouritzin, R. Norman, \& N. Piquemal (Eds.), Qualitative research: Challenging the orthodoxies (pp. 169-181). New York: Taylor \& Francis.

Andrews, B. W. (2010). Seeking harmony: Teachers' perspectives on learning to teach in and through the arts. Encounters on Education, 11, 81-98.

Arts Education Partnership (2001). Strengthening state-level arts education partnerships. Washington, DC: Arts Education Partnership.

ARTS, Inc. \& Performing Tree (2000). Profiles of national models of arts and school connections. Los Angeles, CA: ARTS, Inc.

Bailey, E. (1998). Two stories of collaboration and cross-fertilization. Journal of Museum Education, 23, 16-18.

Berghoff, B., Bergmann, C., \& Parr, C. (2003). Cycles of inquiry in the arts. Language Arts, 80, 353-362.

Best, D. (1995). Collective, integrated arts: The expedient generic myth. Arts Education Policy Review, 97, 32-39.

doi:10.1080/10632913.1995.9935052

Bresler, L. (1992). Visual art in primary grades: Portrait and analysis. Early Childhood Research Quarterly, 7, 397-414. doi:10.1016/0885-2006(92)90029-X

Brophy, J., \& Alleman, J. (1991). A caveat: Curriculum integration isn’t always a good idea. Educational Leadership, 49, 2-7.

Clark, R. A. (1995). Nurturing art education: The efficacy of integrated arts curricula. Canadian Review of Art Education, 22, 1-16.

Conway, C. E., Hibbard, S., Albert, D., \& Hourigan, R. (2005). Voice of music teachers regarding professional development. Arts Educa- tion Policy Review, 107, 11-14. doi:10.3200/AEPR.107.1.11-14

Creswell, J. W. (2002). Research design: Qualitative, quantitative and mixed method approaches (2nd ed.). Thousand Oaks, CA: Sage.

Doherty, P., \& Harland, J. (2001). Partnerships for creativity: An evaluation of implementation. Slough: National Foundation for Educational Research.

Dorn, C., \& Jones, L. (1988). Promoting partnerships in arts education: Teachers, artists and scholars. In J. T. McLaughlin (Ed.), Toward a new era in arts education (pp. 80-90). New York: American Council for the Arts.

Galt, K. (1994). The language of learning. New York: Teachers College Press.

Government of Ontario (1996). Education quality and accountability act. Toronto, ON: Queen's Printer.

Government of Ontario (2012). Putting students first act. Toronto, ON: Queen's Printer.

Gurney, P. J., \& Andrews, B. W. (1998). Building bridges: A case study of policy development in teacher education. In A. Richardson (Ed.), International multiculturalism: Preparing together for the twenty-first century (pp. 50-59). Edmonton, AB: Kanata Press.

Gurney, P. J., \& Andrews, B. W. (2000). Restructuring faculties of education: State of the nation. International Journal for Leadership in Learning, 4.

http://ijll.synergiesprairies.ca/iejll/index.php/ijll/article/view/482

Ingram, D., \& Reidel, E. (2003). What does arts integration do for students? Minneapolis, MN: Centre for Applied Research and Educational Improvement, University of Minnesota.

Irwin, R. L., \& Kindler, A. M. (1997). Beyond the school: Community and institutional partnerships in art education. Reston, VA: National Arts Education.

Jindal-Snape, D., \& Holmes, E. A. (2004). A longitudinal study exploring perspectives of participants regarding reflective practice during their transition from higher education to professional practice. Reflective Practice, 10, 219-232. doi:10.1080/14623940902786222

Kindler, A. (1987). A review of rationales for integrated arts programs. Studies in Art Education, 29, 52-60. doi:10.2307/1320456

McVey, M. K., \& Wilson, M. (1992). Integrated arts: Transition years pilot project. Research project funded by the Ontario Ministry of Education. Ottawa, ON: Ottawa Board of Education.

Miles, M. B., \& Huberman, A. M. (1994). Qualitative data analysis (2nd ed.). Thousand Oaks, CA: Sage.

Myers, D. E. (2005). Preparing performers and composers for effective educational work with children. Arts Education Policy Review, 106, 31-38.

Ontario Ministry of Education (1998). The Ontario curriculum, grades 1-8: The arts. Toronto, ON: Province of Ontario.

Ontario Ministry of Education (2009). The Ontario curriculum, grades 1-8: The arts. Revised edition. Toronto, ON: Province of Ontario.

Oreck, B. (2004). The artistic and professional development of teachers. Journal of Teacher Education, 55, 55-69. doi:10.1177/0022487103260072

Osterman, K. (1990). Reflective practice: A new agenda for education. Education and Urban Society, 22, 132-153. doi:10.1177/0013124590022002002

Patteson, A. (2002a). The creative arts learning partnership evaluation report. Toronto, ON: Learning Partnership.

Patteson, A. (2002b). The creative arts learning partnership evaluation report. Toronto, ON: Learning Partnership.

Patteson, A. (2002c). Amazing grace and powerful medicine: A case study of an elementary teacher and the arts. Canadian Journal of Education, 27, 269-289. doi:10.2307/1602224

Patton, M. Q. (1990). Qualitative evaluation and research methods. (2nd ed.). Newbury Park, CA: Sage.

Pitman, W. (1998). Teaching the arts in an age of uncertainty. Toronto, ON: Ontario Arts Education Council.

Rowe, M. K., Castaneda, L. W., Kaganoff, T., \& Robyn, A. (2004). Arts education partnerships: Lessons learned from one school district's experience. Santa Monica, CA: Rand.

Smithrim, K., \& Upitis, R. (2001). Strong poets: Teacher education and the arts. Journal of Professional Studies, 9, 19-29. 


\section{B. W. ANDREWS}

Stake, R. (1995). The art of case study research. Thousand Oaks, CA: Sage.

Taggart, G., Whitley, K., \& Sharp, C. (2004). Curriculum and progression in the arts: An international study. Slough: National Foundation for Educational Research.

Upitis, R. (2005). Experiences of artists and artist-teachers involved in teacher professional development programs. International Journal of Education \& the Arts, 6. http://ijea.org/

Upitis, R., Smithrim, K., \& Soren, B. (1999). When teachers become musicians and artists: Teacher transformation and professional development. Music Education Research, 1, 23-35. doi:10.1080/1461380990010103

Wilkinson, J. (2000). Literacy, education and arts partnership: A community-system programme integrating the arts across the curriculum. Research in Drama Education, 5, 175-197.

doi:10.1080/713692884

Wilkinson, J. H., Emerson, J., Guillaumant, D., Mergler, J., \& Waddington, J. (1992). Preservice arts teacher education in Ontario. Report prepared for the Ontario Arts Education Council. Toronto, ON: Ontario Arts Education Council. 